\title{
Influence of the Addition of Sand and Compaction on the Mechanical and Thermal Performances of Plaster
}

\author{
Saida Dorbani ${ }^{1}$, Fattoum Kharchi ${ }^{1}$, Fatiha Salem ${ }^{1}$, Karima Arroudj $^{1}$, Nadia Chioukh $^{2}$ \\ ${ }^{1}$ Built Environment Lab.(LBE), University of Bab Ezzouar (USTHB), \\ Faculty of Civil Engineering, Algiers, Algeria \\ ${ }^{2}$ National Agency for the Promotion and Rationalization of Energy Use, Algiers, Algeria \\ E-mail: saidadorbani@gmail.com \\ Received June 11, 2011; revised August 15, 2011; accepted August 25, 2011
}

\begin{abstract}
Since antiquity, man used to stock up materials and products existing in his close surroundings to build his house, which provides him shelter and comfort. Within the present work, mixtures of plaster and dune sand have been studied with the aim of valorization of locally abundant materials. The tests showed that with the addition of dune sand and the compaction, an optimal mixture (67\% plaster and $33 \%$ dune sand) can be used as a carrier element for construction of up to three levels; since significant increase of the mechanical strength has been observed. The element obtained offers an acceptable thermal insulation with a decrease in the thickness of the outer wall construction. The use of this gypsum's mortar block as a carrier element in a structure not exceeding three levels, also enables a considerable savings especially in areas where sand and plaster are abundant and relatively inexpensive.
\end{abstract}

Keywords: Local Materials, Mortar, Plaster, Dune Sand, Compaction, Mechanical Performance, Carrier Element, Thermal Performance

\section{Introduction}

In Algeria, there are several buildings constructed with plaster. The sustainability of these buildings is comparable to that of buildings based with cement in regions where rainfall regime is characterized by alternating short rain and long periods of drying sunny.

Experience has shown that it is possible to mix plaster and sand, in order to achieve savings. However, the properties of new materials obtained are obviously different from those of plaster itself, which implies different means of implementation [1-10,13-14].

The most traditional process of achieving the precasted plaster elements is simple molding, but this one requires a higher mixing ratio for mortar than for the pure gyp-sum, leading to a drop in mechanical strength.

Compaction is a process of consolidation in addition to reducing the amount of mixing water, it reduces also the voids contained in the material itself. This creates an increase in the density and consequently the mechanical properties. Table 1 summarizes the main findings found in the literature on dry and wet resistance to compression of the plaster's mortar.
In this work we study the mechanical and thermal behavior of several mortars based on plaster and dune sand.

\section{Experimentation}

\subsection{Materials}

The materials used in this study are from the south of Algeria. The plaster density is 1.36 , the dune sand one is 2.73 .

The chemical components Table 2 and grading curves Figure 2 are given below.

Table 1. Results listed in the literature.

\begin{tabular}{cccccc}
\hline & & \multicolumn{2}{c}{ Simple casting } & \multicolumn{2}{c}{ Compaction } \\
\hline Ref. & $\begin{array}{c}\text { Morter } \\
\text { Composition }\end{array}$ & $\begin{array}{c}\mathrm{R}_{\mathrm{c}} \\
(\mathrm{MPa})\end{array}$ & $\begin{array}{c}\mathrm{R}_{\mathrm{cH}} \\
(\mathrm{MPa})\end{array}$ & $\begin{array}{c}\mathrm{R}_{\mathrm{c}} \\
(\mathrm{MPa})\end{array}$ & $\begin{array}{c}\mathrm{R}_{\mathrm{cH}} \\
(\mathrm{MPa})\end{array}$ \\
{$[4,5,7]$} & $67 \% \mathrm{P}+33 \% \mathrm{~S}$ & 10.61 & $/$ & 17.9 & $/$ \\
{$[8]$} & $75 \% \mathrm{P}+25 \% \mathrm{~S}$ & $/$ & 3.3 & $/$ & 12.8 \\
{$[9]$} & $28.6 \% \mathrm{P}+71.4 \% \mathrm{~S}$ & $/$ & $/$ & 9 & $/$ \\
{$[10]$} & $30 \% \mathrm{P}+70 \% \mathrm{~S}$ & $/$ & $/$ & 11.5 & 2.5 \\
& $40 \% \mathrm{P}+60 \% \mathrm{~S}$ & $/$ & $/$ & 20 & 5.5 \\
\hline
\end{tabular}


On Figure 1, the grading curves illustrating the granular skeleton of plaster and dune sand, show that the dune sand has a particle size more or less tight (ranging from $80 \mu \mathrm{m}$ to $800 \mu \mathrm{m}$ ) compared to plaster's one.

On the Table 3 are given the compositions and mixing ratio of the mortars simply casted. Plaster is noted $\mathrm{P}$ and

Table 2. Chemical analysis of the plaster and dune sand.

\begin{tabular}{lll}
\hline Components & Plaster & sand \\
\hline Insoluble (silice-silicates) & $2.11 \%$ & $95.05 \%$ \\
Oxyde $\left(\mathrm{Al}_{2} \mathrm{O}_{3}, \mathrm{Fe}_{2} \mathrm{O}_{3}\right)$ & $0.8 \%$ & $1.2 \%$ \\
$\mathrm{CaSO}_{4}$ & $89.42 \%$ & Traces \\
$\mathrm{NaCl}$ & $0.23 \%$ & $0.29 \%$ \\
$\mathrm{Carbonates}\left(\mathrm{CaCO}_{3}\right)$ & $1.68 \%$ & $2.52 \%$ \\
$\mathrm{CO}_{2}$ & $0.73 \%$ & $1.10 \%$ \\
$\mathrm{Perte}$ au feu à $1050^{\circ} \mathrm{C}$ & $8.33 \%$ & $1.3 \%$ \\
$\mathrm{H}_{2} \mathrm{O}$ & $7.6 \%$ & $0.2 \%$ \\
\hline
\end{tabular}

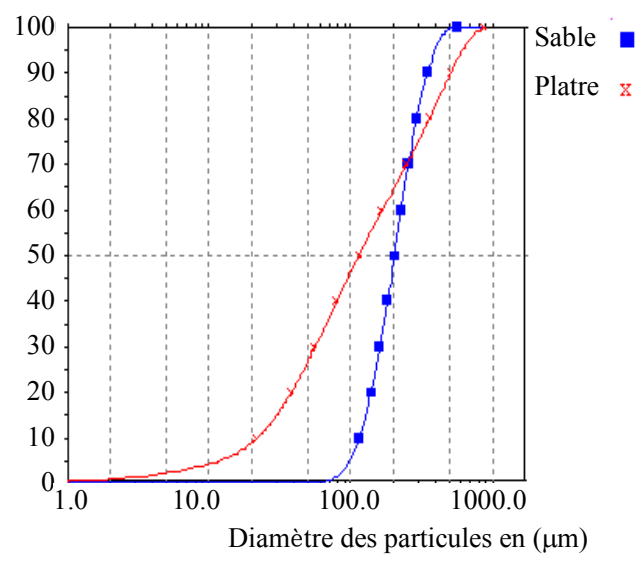

Figure 1. Grading curves of the plaster and sand.

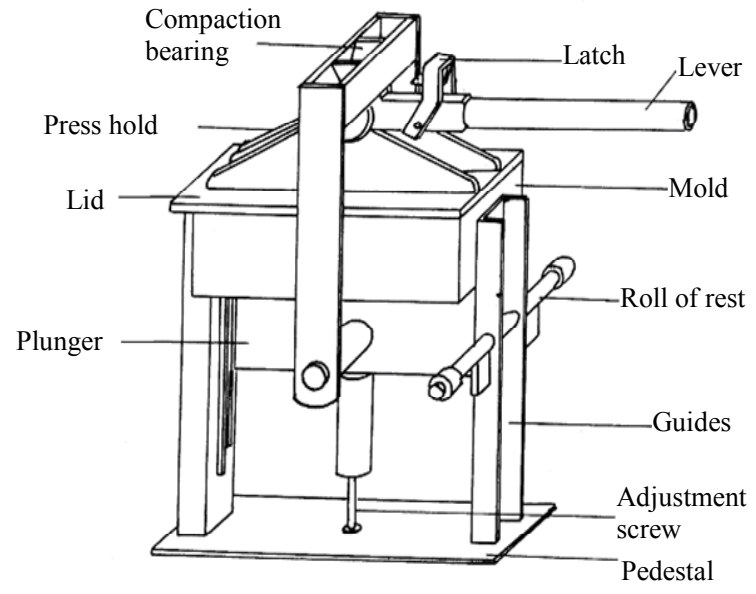

Figure 2. Manual Compacting Press.
Table 3. Compositions and mixing ratio of the mortars simply casted.

\begin{tabular}{ccccc}
\hline & Reference & W/B (\%) & $\%$ P & $\%$ S \\
\hline \multirow{4}{*}{ Plaster } & M1 & 58 & 100 & 0 \\
& M2 & 75 & 67 & 33 \\
Plaster Mortar & M3 & 88 & 50 & 50 \\
& M4 & 126 & 33 & 67 \\
\hline
\end{tabular}

sand is noted $\mathrm{S}$. W for water and B for binder (plaster in our case)

According to the tests to be carried out; we conceived three different sized specimens:

\subsection{Tests}

\subsubsection{Mechanical Tests}

Simply casted

In accordance with ISO DIS 3051 and 527 NA [11-12] "Plaster: determination of mechanical properties." The specimens for mechanical testing are prismatic with the following dimensions:

Length: $160 \mathrm{~mm}$;

Width: $40 \mathrm{~mm}$;

Thickness: $40 \mathrm{~mm}$.

\subsubsection{Thermal Tests}

To determine the thermal conductivity we used two different techniques: the method of the boxes and that of CT meter.

The samples were parallelepipeds of: $270 \mathrm{~mm}$ wide and $50 \mathrm{~mm}$ for measuring the thermal conductivity by the boxes method and $110 \mathrm{~mm}$ side and $50 \mathrm{~mm}$ thick for the measure with the $\mathrm{CT}$ meter. The results obtained by both methods are similar.

As various studies published on the plaster mortars, $[1-10,13,14]$ it was found that:

- The addition of sand makes the mixture thicker and increases the mixing ratio $\mathrm{W} / \mathrm{B}$ required to obtain a given consistency, which slowed the setting of the plaster.

- No improvement of the mechanical performance depending on the addition of sand (14MPa for the plaster to $2.92 \mathrm{MPa}$ for the mortar containing (maximum of sand) $67 \%$ sand and $33 \%$ gypsum). In addition, the bad adherence between the gypsum particles and sand caused the erosion of the specimens.

Compaction

To obtain plaster's mortars, with an important dosage of sand, and insuring at the same time a good mechanical strength, it is necessary to develop new processes for implementation; in order to run quickly with the mini- 
mum need for water. The compaction seems being a good solution [1-10]. The Table 4 gives the compositions and mixing ratio of the compacted mortars.

Compaction is performed on fresh material, through a manual press designed originally for the manufacture of Concrete of Stabilized Earth Figure 2, adapted to our needs. The manufactured specimens have specific dimensions of $110 \mathrm{~mm}^{2} \times 230 \mathrm{~mm}^{2}$ and a thickness "e" which varies from $35 \mathrm{~mm}$ to $80 \mathrm{~mm}$.

The specimens for the different tests (mechanical, and thermal), were collected by cutting as adequate samples sizes for each test. The specimens for the different tests have been kept since mold release and throughout the period preceding the tests in a closed area, where we guaranty a uniform relative humidity and a constant temperature. Those for the determination of wet per- formances ( $\mathrm{RCh}$ et $\mathrm{RfH}$ ) were immersed for $48 \mathrm{~h}$ before the test.

\section{Results}

\subsection{Mechanical Strength}

Due to the compaction process, considerable improvements are noticed. We recorded significant improvement in mechanical strength of all mortars including plaster itself, taken as a reference material, which is in consistency with the literature [1-10]. This improvement appears since the young age and grows significantly with a pronounced slope until the 14th day, where it becomes less accentuated. In the following figures, we note the bending resistance noticed $\mathrm{Bs}$ and compressive strength noticed Cs. The indexes $0,1 \mathrm{mn}$ and $5 \mathrm{mn}$ represent the compaction duration

For mortar named M2, we were able to achieve more than $7 \mathrm{MPa}$ in bending strength, which represents an evolution from $28 \%$ to $31 \%$ respectively for $1 \mathrm{mn}$ and $5 \mathrm{mn}$ of compaction compared to the same mortar simply sank. As for the compressive strength, we managed to achieve over $20 \mathrm{MPa}$, the equivalent of an increase between $62 \%$ and $68 \%$ for the same time compacting raised as illustrated in Figures 3 and 4.

It should be reported that in terms of moisture, the behaviour of materials based on plaster is very different

Table 4. Compositons and mixing ratio of mortars compacted.

\begin{tabular}{ccccc}
\hline & Reference & W/B $(\%)$ & $\% \mathrm{P}$ & $\% \mathrm{~S}$ \\
\hline Plaster & M1 & 20 & 100 & 0 \\
\multirow{3}{*}{ Plaster Mortar } & M2 & 25 & 67 & 33 \\
& M3 & 32 & 50 & 50 \\
\hline
\end{tabular}

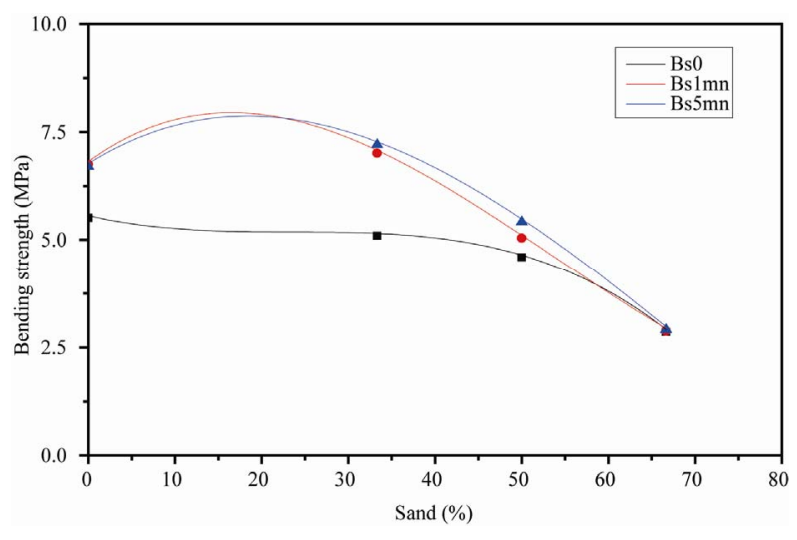

Figure 3. Bending strength of dry plaster mortar.

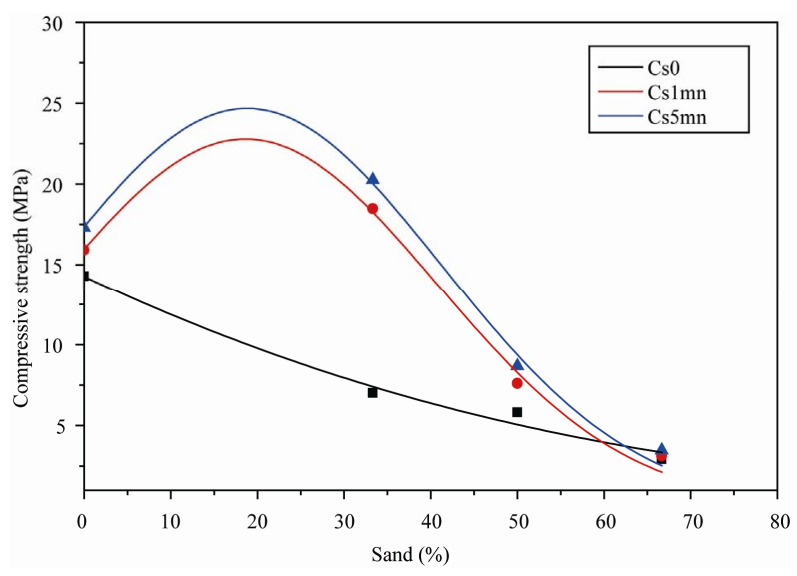

Figure 4. Compressive strength of dry plaster mortar.

from the materials based on cement.

- A wetted concrete cement marks a very weak decrease in its mechanical properties;

- The mechanical properties of a material based on plaster falls by the presence of moisture, that is why, we must consider the mechanical characteristics obtained in wet state.

That's why, in the dimensioning of plaster structures especially the carrier elements, we must take into account the wet performances.

However it should be noted that for specimens, despite the wide gap that still exists between the wet and dry mechanical performances as shown on the Figures 5 and 6; the compaction has kept them (even those acquired after 48 hours of immersion) beyond the threshold imposed by the recommendations of plaster building.

This positive effect is explained when we understand that it is the porous structure of plaster which is the source of its great sensitivity to water, in front of this major inconvenience, compaction was a major point by reducing the volume of voids in the crystal structure.

It has prevented water from penetrating deep Hence a reduction between $15 \%$ and $30 \%$ of its water absorption, 


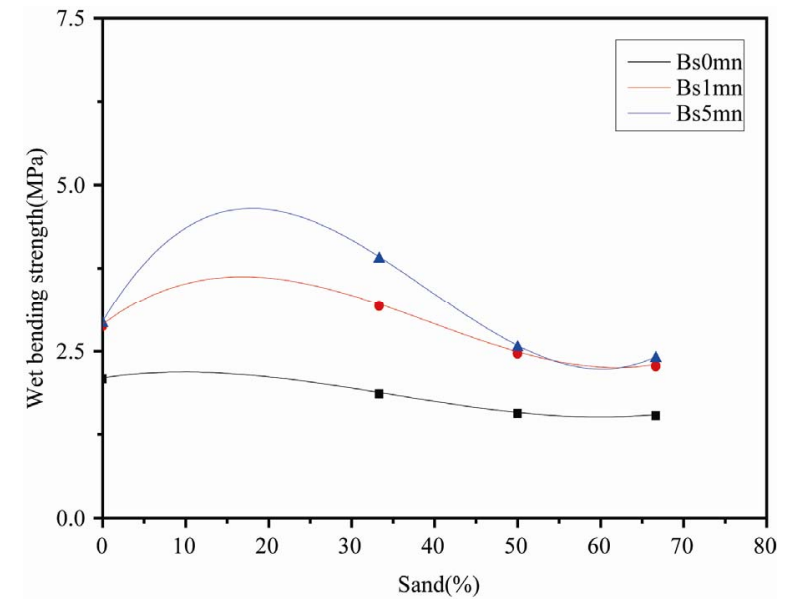

Figure 5. Bending strenght of plaster mortars in wet state.

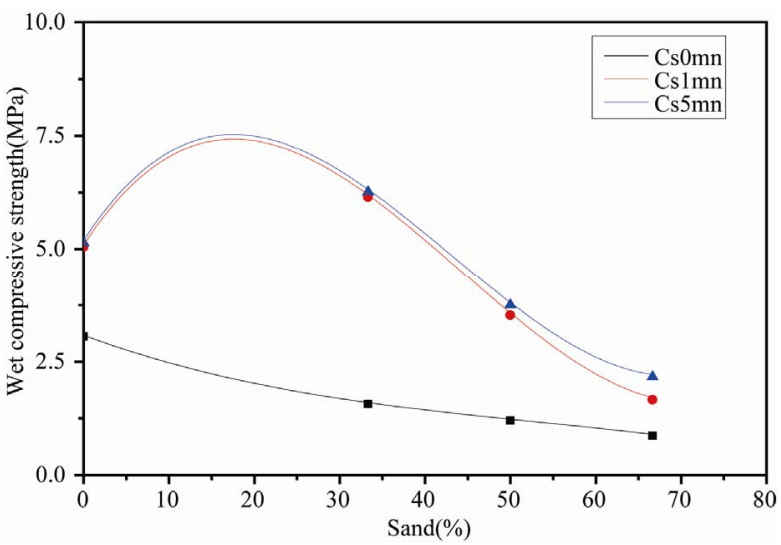

Figure 6. Compressive strength of plaster mortar in wet state.

this allows ease of evaporation later, making the material two to three times less capillar and its speed is reduced by saturation rate ranging from $20 \%$ to $60 \%$.

\subsection{Thermal Performances}

The thermal performances (thermal conductivity Figure $\mathbf{7}$ and resistance Figure 8 were also significantly influenced by the addition of sand. This addition acted adversely on the thermal conductivity. This one has evolveed positively to low slope with the sand addition [2,3,7].

With an implementation by compaction, thermal conductivity at different sand dosages undergoes a more important evolution; the new values are almost double the same mortar simply casted. This increase is induces by the density increment which occurs following the reducetion of volumes of voids by the compaction.

Knowing that the thermal resistance is inversely proportional to the thermal conductivity and a material is more insulating when its thermal resistance is large. This representative performance for the various mortars

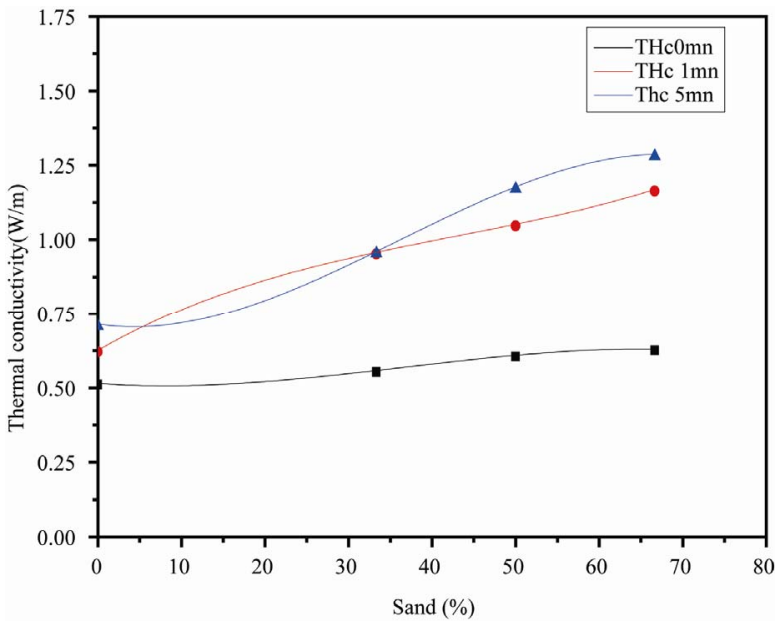

Figure 7. Thermal conductivity of various plaster mortars at different times of compaction.

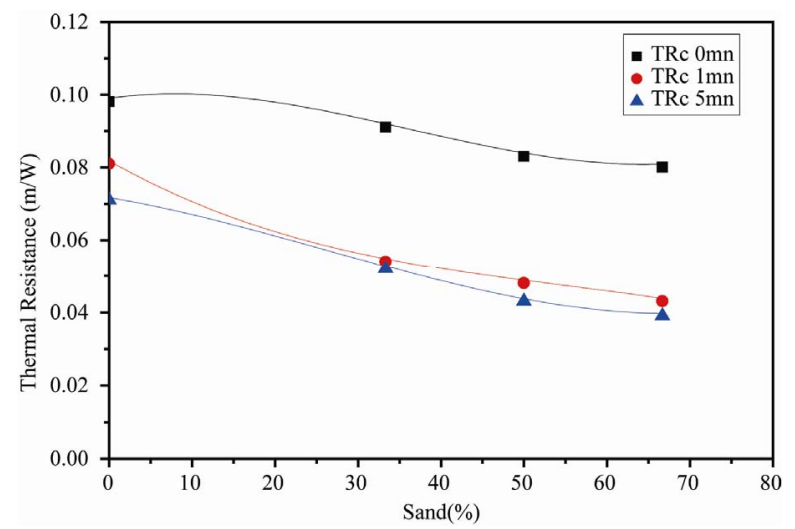

Figure 8. Thermal resistance of various plaster mortars at different times of compaction.

including the pure plaster, fell with the addition of sand and this decrease is more significant for larger time of compaction.

\section{Conclusions}

The optimum between mechanical and thermal characteristics is obtained for the mortar called M2, despite its decreased thermal performance; it is the mortar that marked the better thermal performance and gives an acceptable thermal insulation compared to the two most commonly used materials in construction: the hollow brick and concrete with an $\mathrm{M}_{2}$ double bulkhead $0.30 \mathrm{md}$ thickness separated by an air space of $0.05 \mathrm{~m}$, and the resulting wall is too broad.

Its thermal efficiency is specifically improved, when we adopt a provision in double walls of of $0.15 \mathrm{~m}$ of this mortar separated by a plate of polystyrene $0.05 \mathrm{~m}$. Insulating capacity increases. The wall thermal resistance increases and becomes twice more important than that of 
the wall of hollow brick aforesaid.

Also the use of this plaster mortar as carrier element in a structure which does not exceed three levels, allows considerable saving particularly, in the regions where sand and plaster are relatively abundant and cheap. That should procure a significant number of advantages such as:

- The development of natural resources and the opportunity of conducting an independent policy of building;

- No need to use complicated technologies, therefore no necessity to use a high qualified Workforce.

- The lightness of elements, which is a valuable quality for the workforce and enables saves on transport and handling equipment.

- Regulating the whole national economy, while providing reasonable solutions to the problem of housing;

\section{Recommendations}

To build with mortar plaster [1]:

- We must ensure the quality of soil foundations by a preliminary geotechnical study;

- In presence of water in the vicinity of the construction, it is essential to have a drain table;

- The foundations are made of materials unalterable to water (reinforced concrete, masonry or stone rubble);

The bearing walls should be arranged as much as possible symmetrically to the main axis of the building.

\section{References}

[1] M. Nolhier, "Building with Plaster," Éditions L'Harmattan, Paris, 1986, p. 305.

[2] S. Dorbani, "Contribution for Improvement of Mechanical and Thermal Performance of a Gypsum Mortar," Magister Thesis, University of Science and Technology Houari Boumediene, Algiers, 2004.

[3] S. Dorbani, F. Kharchi and F. Salem, "Building with Plaster," Proceeding of the XIth Maghreb Days of Materials Science, JMSM Mahdia-Tunisia, November 2008.
[4] S. Dorbani, F. Kharchi and F. Salem, "Plaster Mortar," Standards and Requirements Techniquesdans the Building, Civil Engineering and Hydraulic BTPH 02, 3 July 2005, Sidi Fredj.

[5] F. Kharchi, "Mortar of Sand and Plaster-Economic Materials," 1997 International Conference on Engineering Materials, Ottawa, 8-11 June 1997.

[6] F. Kharchi, "Saharan Housing with Plaster and Sand," International Congress on Modern Techniques and Their Role in the Development of Rural Housing and Sahara in the Arab World, Tripoli Lybie, 10-12 October 2000.

[7] F. Kodja and M. Houanti, "Study for the Improvement Mechanical and Physical Characteristics of Plaster," Engineering Thesis, Institute of Civil Engineering, University of Science and Technology Houari Boumediene, Algiers, 1992.

[8] B. Meddah and K. Meddah, "Contribution to the Study of Gypsum-Improved of Mechanical and Physical Characteristics by Compaction," Engineering Thesis, Institute of Civil Engineering, University of Science and Technology Houari Boumediene, Algiers, 1993.

[9] C.E.B.T.P, "Manufacture and Use of Gypsum Cooked by Drying," Plan de Construction REXCOOP, Paris, 1984.

[10] A. Acceta, N. Jacquetet and C. Pettang, "Dynamic Compaction of MortarSand/Plaster "Production Center Dynasty," Symposium Building with Plaster in Developing Countries, Paris, 1985.

[11] J. M. Brouard, "Determination of the Influence of the Annoyed Expansion on the Mechanical Performance of Plaster Mortars," Reporting of C.E.B.T.P and L.C.P.C Laboratories, Paris, 1987

[12] International Standardization Organization, "Plaster: Determining of the Mechanical Characteristics," ISO DIS 3051.

[13] Algerian Standards, "Plaster: Determining of the Mechanical Characteristics," NA 527.

[14] W. Albercht and W. Steinbach, "Influence of Sands on the Begining of Setting of Plaster Mortar," CERILH Translation of a Paper in Zement Kalk Gips, No. 4, 1961.

[15] W. Karger, "Caracteristiques of Building Components with Emaciated Plaster Depending on the Lowering of the Open Water," Bauakademie der D.D.R, l'institut fûr Baustoff, Weimer, 1975. 